Lewis, C., \& Carpendale, J. I. M. (2009). Introduction: Links between social interaction and executive function. In C. Lewis \& J. I. M. Carpendale (Eds.), Social interaction and the development of executive function. New Directions in Child and Adolescent Development, $123,1-15$.

\title{
Introduction: Links Between Social Interaction and Executive Function
}

\author{
Charlie Lewis, Jeremy I. M. Carpendale
}

\begin{abstract}
The term executive function is used increasingly within developmental psychology and is often taken to refer to unfolding brain processes. We trace the origins of research on executive function to show that the link with social interaction has a long history. We suggest that a recent frenzy of research exploring methods for studying individual executive skills should pay more attention to the tradition exploring the role of social interaction in their development. () Wiley Periodicals, Inc.
\end{abstract}


Inhibition is therefore a history of the relation, as embodied in language, between specialized claims about nature and social values. There has indeed been a common discourse over the last two centuries or so for the science and morality of control within the individual person and in political economy

—Smith (1992), p. 228, his emphasis

$\mathrm{P}$ sychologists in the past 20 years have homed in on a group of skills that control our actions and thoughts, under the banner "executive function." The cognitive "revolution" of the 1950s was heralded in books such as Broadbent's Perception and Communication (1958); it presented a psychology in which the aim was to study the flow of information from the sense organs to the individual's response. This information-processing approach came under revision in the 1970s and 1980s with the inclusion of supervisory systems that regulate the flow of information and control behavior, as we see, for example, in the working-memory model of Baddeley and Hitch (1974; Baddeley, 1886) or Norman and Shallice's Supervisory Activating System (1980). Such control mechanisms have become central to the make-up of executive function and refer to a number of interrelated skills.

We briefly describe these skills here. First, working memory refers to the capacity not only to hold information in mind but to be able to report it in a way that is not simply rote repetition. Attentional flexibility or "set shifting" is the ability to change from one way of solving a problem to another complementary means. Inhibitory control refers to the propensity to suppress prepotent responses, as in hurrying to copy an adult even if he or she has not prefaced an instruction, in the popular game, with "Simon says." Planning is often taken to be the superordinate executive skill because to perform complex actions such as completing a shopping trip or cooking a complex meal involves a combination of all these skills.

Increasingly the topic of executive function has been explored in terms of its neural correlates and is seen by some as a new way of examining the higher levels of cognitive processing. Yet, rather than being the new kids on the block, these constructs have a long tradition, one that is not well documented in the history of psychology. A cursory look at this history is sufficient to show that executive function has been eminent in psychology, with the roles of cognition and social interactions identified as intertwined. For a start, concepts such as inhibition and control were repeatedly used in the study of the mind long before Freud focused on mental processes that constrain our natural impulses. Roger Smith's detailed and fascinating history of one strand of executive function, inhibition, shows that over the 19th century the term originated in moral debate about the control of behavior, gradually filtering into discussion in neurophysiology from the 1830s and into development of psychology in the late 19th century. Smith (1992, pp. 68-69) shows that even early analyses of the reflex, published in the 1830s, focused on a "higher" regulatory system for control of behavior. He also 
points out that executive processes are discussed at length in William James's Principles of Psychology (1890). Smith's history is important because he shows the continuing fault lines in constructs such as inhibition that can be extended to all areas of executive function. These issues concern the relative roles of social processes, social learning, and physiological processes in development of control and the nature of the executive system itself.

The authors in this volume represent a continuing strand of studies attempting to bridge the gap between social interaction and executive function, and thus to get a better grasp of how the two constructs relate to each other. In this chapter we briefly present an analysis of the origins of current work exploring the role of social factors in executive function. The first main section examines the theoretical debate we feel has informed such recent analyses but not been given pride of place in them. The second part explores some key methodological issues, to address how we measure executive skills in children and how our measurements might be improved. In the final and briefest section, we attempt to situate the chapters in this volume in terms of our theoretical and methodological analyses.

\section{Theorizing the Links Between Social Interaction and Executive Function}

Interest in development of executive function has primarily taken a neuropsychological perspective, but researchers in this new wave of research are beginning to consider the possible role of social interaction in such development. This is actually a return to the view emphasized by a researcher whose pioneering work on conceptualization, measurement, and remediation of executive functions has had a major influence on contemporary research, Alexander Luria (e.g., 1961). The reason we start this introduction with a reference to a longer history is that Luria drew on a tradition of theory in which a central issue was the role of social processes in executive skills. In the early 20th century, there was much discussion about the evolutionary function of executive skills. Mead (1910, p. 178) suggested that "human conduct is distinguished primarily from animal conduct by that increase in inhibition which is an essential phase of voluntary attention, and increased inhibition means an increase in gesture in the signs of activities which are not carried out; in the assumptions of attitudes whose values in conduct fail to get complete expression." A similar point was made by Vygotsky (1978, p. 28).

Indeed, it is Vygotsky's theory that we believe has informed the thinking behind the research reported in this book and the theoretical implications of this work, although his influence remains somewhat hidden in contemporary debate. Like Mead, Vygotsky characterized intelligent human activity as the ability to deliberate between alternative response actions. Such skill requires the person to distance herself or himself from the types of immediate reaction to the world that are seen in animals or in people who make "unthinking" prepotent responses. Language and related symbol 
systems, learned and maintained through social interaction, are central to the process of gaining self-control via what Vygotsky (1978) terms "higher" cognitive processes, notably planning, memory, and inhibition.

Thus for Vygotsky development of executive function is a natural consequence of social learning. Simple actions such as tying a knot in one's handkerchief or making a shopping list transform biologically given skills such as "natural memory" into more versatile higher functions that are mediated by signs. Thus social interactions and social conventions drive cognitive development and link the individual into historical and cultural traditions. This "permits humans, by the aid of extrinsic stimuli, to control their behaviour from the outside. The use of signs leads humans to a specific structure of behaviour that breaks away from biological development and creates new forms of a culturally-based psychological process" (Vygotsky, 1978, p. 40, emphasis in original). The lesson of Vygotsky's theory is that it is a mistake to consider executive processes in isolation from the individual's psychosocial functioning. As Luria (1981, p. 89) put it: "We must go beyond the limits of the individual organism and examine how volitional processes are formed for the child in his/her concrete contacts with adults. . . The source of the volitional act is the child's communication with adults. . . The volitional act: not initially a mental act, not a simple habit: rather it is mediated by speech."

More systematic historical research is needed, but it is clear that an initial interest in developmental research on the Vygotsky-Luria hypothesis following its introduction to the West did not receive complete support. Miller, Shelton, and Flavell (1970) did not find support for Luria's claims that speech helps the child regulate her behavior. Other research produced more positive evidence, particularly that of Walter Mischel and Ignatius Toner in two series of studies on the role of arousal and motivation toward delay of gratification. In Mischel's work, children could delay gratification if they reflected on suppressing the temptation, rather than focusing on performance of the task (Patterson \& Mischel, 1976) or if asked to imagine a reward as something else (e.g., Mischel \& Baker, 1975). Toner explored the effects of children's motivation in another delay-of-gratification procedure (Ritchie \& Toner, 1984; Toner, Moore, \& Emmons, 1980; Toner \& Smith, 1977). Before the task, the experimenter said to the preschooler either that he had heard the child was, for example, patient (a task-relevant remark) or that she had a lot of friends in the preschool (a task-irrelevant remark). The assessment involved how long it would take the child to grab for candies that were designated as the child's and whose pile was added to every 30 seconds. Toner found that children in the group in which the experimenter made a task-relevant remark waited significantly longer to claim the candies allocated to them and therefore obtained a larger reward. This effect was obtained even when one experimenter made the remark and a second experimenter, unaware of which remark had been made to the child, administered the delay-of-gratification task. 
This work on delay of gratification shows the roles of social interaction and the child's motivation in development and use of executive skills. Research exploring development of self-regulation, or how children gain control over their behavior, has carried on the social interaction tradition and merged it with others. It has assumed that this developmental process starts with the interactions between children and their caregivers (Kopp, 1982; Rothbart \& Derryberry, 1981). This term emerged as a result of research showing that toddlers between one and two years old become aware of the demands on social control that are negotiated with their parents. A recent meta-analysis shows there is a gradual transfer from external to internal processes that can be seen within the framework of developing attachments (Karreman, van Tuijl, van Aken, \& Dekovi, 2006).

These strands of research, on delay of gratification and self-regulation, have maintained a trickle of interest in the role of social interaction in selfcontrol. However, we think it is fair to suggest that as work on executive function progressed it became less social and more individualistic and located purely within neuropsychological pathways (e.g., Aron, 2008). This is partly due to development of procedures for measuring neurological activity, such as MRI and PET (used primarily with adults) and EEG. These techniques suggest that executive skills are located in specific areas of the brain, particularly in the frontal lobes, and are revealing interesting separations and links (e.g., Knight \& Stuss, 2002). Second, as Zelazo, Müller, Frye, and Marcovitch (2003) point out, a majority of the research on executive functions over the past two decades has adopted what they term an "empirical" approach in which the focus of attention is on devising a test for one of the component skills of executive function. For example, Gerstadt, Hong, and Diamond (1994) constructed a measure called the Day-Night task to assess the construct of inhibition discussed at the start of the chapter. Children were presented with a series of pictures of the sun on a white background or the moon or stars on a black card. Participants had to say "day" to the moon and "night" as soon as a card with the sun was revealed. In keeping with the idea that children gain increasing inhibitory control over the preschool years, Gerstadt and colleagues found a sharp rise in the ability to resist the temptation to label the tasks in keeping with picture of the card (i.e., "day" to the sun), which they attributed to developments in the connections made in the prefrontal cortex. However, they also reported that social interactional factors influenced the performance of children. Those in day care did better than those raised exclusively at home, suggesting that something about extrafamilial care and a greater number of peer interactions might facilitate the rate of acquisition of key executive skills. Since that study, other social correlates with executive skills have been identified, particularly socioeconomic status (e.g., Ardila, Roselli, Matute, \& Guajardo, 2005; Noble, McCandliss, \& Farah, 2007), but in the main such links have been overlooked. 
In this section, we have argued that the social basis of executive function receives less attention than one might expect given the historical backdrop of research from Luria and Vygotsky (Zelazo et al., 2003). Theoretical analyses in keeping with that tradition, such as that of Zelazo and Jacques (1996), became the exception rather than the rule. Although this has changed very recently (Fernyhough, in press; Landry \& Smith, in press; Lewis, Carpendale, Towse, \& Maridaki-Kassotaki, in press; Sokol \& Müller, 2007), we see the theoretical issues raised in this volume as a resurgence of the Vygotsky-Luria tradition, rather than as a continuation of the tradition inspired by the trickle of work described here. We turn now to more recent preoccupations.

\section{Methodological Issues in Analysis of Executive Function}

The main impetus behind the recent phase of research into development of executive function has come from within the "cognitive revolution's" attempt to understand the mind-brain system. No doubt this tradition will develop apace in the coming years, but we discuss here the grounds for maintaining the dimension of social interaction within models of the development and nature of these skills.

Much of the recent work has explored the cognitive architecture of the executive system to determine whether we can distinguish between individual skills that make up that system. In recent years there has been some consolidation of evidence and theory on the topic. An influential paper by Akira Miyake and his colleagues (Miyake, Friedman, Emerson, Witzki, Howerter, \& Wager, 2000) examined whether and how the components of executive function fit together, using structural equation modeling to find the best way of relating each component to the others. In adults they found that the individual skills described at the start of the chapter (working memory, attentional flexibility, and inhibitory control; they use other terms but we use these to be consistent with the literature in developmental psychology) should be treated as separate entities, but the best model was one in which they all fit together into a superordinate construct "executive function," including planning. They termed this a "unity-with-diversity" model, as each individual variable was distinct but needed to be correlated with the others.

Miyake et al.'s model (2000) was constructed on large amounts of data collected from adults. They have since shown a high level of stability between childhood and adolescence (Friedman et al., 2007), and an even higher heritability of adult executive functioning was identified in an adult-twin study (Friedman, Miyake, Young, DeFries, Corley, \& Hewitt, in press). However, we must be cautious about generalizing from these relatively stable data in adults to executive function in children; nor should we simply assume that there is an equivalence between adult and child executive skills, or that the latter develop within a social vacuum. We examine each of these issues in turn. 
How well do definitions of executive function derived from research on adults transfer to children? One study of older children (Lehto, Juujarvi, Kooistra, \& Pulkkinen, 2003) echoed Miyake's findings (2000) in terms of a unified system of skills in working memory, attentional flexibility, and inhibitory control. Yet Huizinga, Dolan, and van der Molen (2006) failed to find that measures of inhibition in children were related to other executive skills. So the jury is still out on whether there are commonalities between adults' and children's executive skills. Such differences reveal further issues and potential problems. For a start, simply assuming that tests are measures of only one construct is not sufficient, particularly when examining measures designed to be childfriendly. Discussion of what is referred to as "task impurity" (e.g., Rabbitt, 1997) suggests that tasks designed to test one construct often necessarily involve other abilities. For example, tests of inhibitory control and set shifting almost necessarily involve a degree of working memory, as the child has to recall which responses to make and which to inhibit. The Day-Night test (Gerstadt, Hong, \& Diamond, 1994), described earlier, contains a control condition that, in theory, allows researchers to extract the effect of extraneous working memory skills, as it involves recalling the two words day and night arbitrarily assigned to one of two abstract patterns. Yet researchers usually pay little attention to these conditions. Our attempt to do so suggests a close correspondence between the Day-Night pictures and the versions with two abstract patterns, thus suggesting that the latter does not simply take out the working memory component of the former (Lewis, Solis-Trapala, Shimmon, $\&$ Diggle, in progress; Shimmon, 2005). Furthermore, attempts to measure test-retest reliability (Bishop, Aadmodt-Leeper, Cresswell, McGurk, \& Skuse, 2001) and the correspondence between related tests (Bull, Espy, \& Senn, 2004) have been low, thus leading to questions about the consistency of children's performance, at least in terms of more complex executive tasks involving planning. We explore individual tasks in the rest of this section.

First, we feel that these issues concerning test construction and reliability raise more fundamental questions about the nature of executive skills and how we measure them. If these skills are about continuous processes (such as keeping something in mind, anticipating a need to change a response to environmental stimuli, or inhibiting the desire to open the cookie jar), then we should consider thinking about the psychological dimension of such skills dynamically and designing measures that tap into such dynamics. As Zelazo and Müller (2002) note, a construct such as inhibition does not specify how the process of inhibition is selected and used by the individual. Let us look at the second issue first.

How can we tap into the dynamics of executive processes? Towse, Lewis, and Knowles (2007) considered this question in relation to a phenomenon common to both young children and the elderly, concerning the struggle with remembering to follow an action in response to an anticipated prompt. We modified a paradigm known as goal neglect (Duncan, Emslie, 
Williams, Johnson, \& Freer, 1996) in which children had to identify food items that appear every few seconds in two houses identified as a target by a cue (e.g., an arrow) as to which house to identify the items in. The children knew there would be a second cue (e.g., a blue or red square to identify the color of the house) to indicate whether to keep naming the food items in the same house or switch to naming them in the second. Participants also were assessed on a test of set shifting and a measure of inhibitory control. Two findings are relevant here. First, the two cues related differentially to the other executive tests. Responses to the first cue (the ability to follow a simple command) were correlated with the measure of conflict inhibition (a test like the Day-Night task), while the second cue correlated with set shifting as measured by the Dimension Change Card Sort (DCCS; Frye, Zelazo, \& Palfai, 1995; see below), in which the child has to sort a series of cards by color and then sort them by shape (or vice versa). This suggests that there is some mileage in considering children's performance by examining the dynamics of test performance (Towse et al., 2007).

Second, the type of cue used to direct children's attention influenced their compliance. Participants made more errors in response to a color cue than an arrow, presumably because the arrow is more directive. These data suggest that the child's executive functions can be directed by "external" influences, which raises the question of how extensive these external conditions are. Indeed, the findings lead to two possible ways by which such cues influence the child's self-regulation, and both tie into Vygotsky's theory: the role of others in guiding the child into areas of self-controlled activity and the part played by symbolic processes in higher-level mental functions.

Despite a shift in focus over the past quarter century toward the nature of tests of executive skills, the recent research described here keeps leading us back to a more socially embedded perspective. The DCCS task is a good example. In this procedure, children are asked to sort cards, differentiated by shape and color, into one of two trays. After six sorts, the sorting criteria are changed (from color to shape or vice versa). Three-year-olds typically continue to sort cards by the first (preswitch) rule, even if only one or two preswitch trials are performed (Frye et al., 1995). Indeed, responses tend to be bimodal, suggesting that children either get the rule or do not. Frye et al. interpret these findings as suggesting that young children's failure on this task and older children's success can be attributed to development of an ability to construct higher-order rules that make up two rule systems (e.g., the shape and color rule sets) accessible to conscious control. This is known as Cognitive Complexity and Control (CCC) theory.

The DCCS procedure has been replicated many times (see Zelazo et al., 2003, for a recent summary of theory and data), and the CCC theory is open to the possibility that the child gains an understanding of the higher-order rules through social interaction. However, the theory is not without its detractors (e.g., Kirkham, Cruess, \& Diamond, 2003; Munakata \& Yerys, 
2001), some of whom propose more socially embedded explanations for the developmental shifts seen between the ages of three and four. Three studies, for example, emphasize the interaction between child and experimenter in managing the child's performance. The first, by Towse et al. (2000), suggested that if three-year-olds are given more support to understand the postswitch rules (explained in the same way that the preswitch rules were), their level of performance improved greatly. Likewise, Brace, Morton, and Munakata (2006) found that demonstrating the correct response was more successful than giving the standard instruction, suggesting that something about the experimenter-child interaction scaffolds the child's activity, in some circumstances facilitating successful performance.

Perhaps the clearest recent demonstration of the effects of social interaction on the DCCS performance of three-year-olds comes from a series of four experiments published by Moriguchi, Lee, and Itakura (2007). Previous work had found no effect of placing the DCCS task into an interactive context. For example, Jacques, Zelazo, Kirkham, and Semcesen (1999) had found that three-year-olds were inaccurate in their judgments of a puppet's successful or unsuccessful performance in the postswitch trials. In Moriguchi et al., witnessing an adult model making errors on the preswitch trials led to children making fewer errors while following the same rule on the postswitch trials themselves. So the correct strategy was to use the sorting strategy they had not seen being used. They manipulated the procedure to test whether there was an effect of the actor expressing awareness of errors or confidence in performance. Moriguchi and colleagues found that these social factors had a dramatic influence on performance. So, having sorted the cards incorrectly, if the actor says she was right in her sorting then almost $80 \%$ of three-year-olds failed, while if the actor says she made a mistake or is not sure then $80 \%$ of three-year-olds' performance jumped to a ceiling level. This study is a timely reminder of the potential influence of social interactions on children's performance in executive tasks. Interestingly, it has a resonance with a series of Russian studies in the Vygotsky-Luria tradition that have not been translated into English (e.g., Subbotsky, 1976). In one such study, when a child performs a version of Luria's hand game with an experimenter and an adult confederate, if the confederate performs the wrong gesture a majority of five-year-olds will err by copying him even though most will succeed when doing the task without the confederate present.

How do these social interaction processes influence children's executive skills? The three manipulations of the DCCS just discussed share a structure in which the adult scaffolds the child's performance, but we need to explore how this works. A Vygotskian interpretation would hold that the interaction between adult and child permits the latter to gain some symbolic mastery, and therefore control, over his or her actions. The DCCS does not easily lend itself to manipulations, which allow exploration of the effect of symbolic representation on preschoolers' understanding. However, there is 
a collection of tasks examining the child's ability to inhibit a prepotent response that facilitates such manipulations. Often termed conflict inhibition, in these tasks the child has to choose the less rewarding stimulus in order to receive the greater reward. For example, in Carlson, Davis, and Leach's procedure (2005) the child needs to point to the smaller number of treats in order to receive the larger number when two alternatives are presented. Three-year-olds have a problem either pressing a button before reaching into a box for a treat (Hughes \& Russell, 1993) or pointing to an empty box when there is another with a candy in it (Russell, Mauthner, Sharpe, \& Tidswell, 1991). What happens when the task involves a symbolic cue to guide children to an understanding of the task?

Carlson et al. (2005, experiment 2) gave children a task in which they could win two candies or five. In one condition the candies were on the top of a box, while in three other conditions they were concealed inside the boxes, with a symbolic representation on the top of each to represent the contents: two or five stones, a few or many dots, or a mouse and an elephant to represent the number of sweets inside. Interestingly, Carlson et al. found that the mouse-elephant condition led to greatest success (significantly more than the real-treat condition) and in this and the dots conditions children were significantly above chance. The overall findings suggested that use of symbolic moderation can help preschoolers give a correct answer, presumably because the symbol allows or forces them to distance themselves from the reward. These findings are in keeping with similar experiments in which children use a symbol such as a model pointing hand to identify the box without a reward, in the Windows Task (Hala \& Russell, 2001).

\section{Increasing the Focus on Social Interaction and Executive Function}

To summarize our analysis thus far: research on development of executive skills was based on a tradition that assumes such skills are embedded in social processes, but this tradition has been somewhat sidelined as researchers become increasingly focused on measurement of the components of executive function and their possible relation to neurological pathways. The aim of this volume is to present some current research that highlights the resurgence of an approach to the topic that takes social interactions and social relationships as the starting point. What follows is a selection of four chapters and a discussion attempting to home in on different aspects of the social interaction-executive function relationship in an attempt to draw the reader's attention to its complexity rather than furnish definitive answers.

In this volume, we start off with an examination of the dyad and move continuously outward, in part across the span of childhood but mainly in terms of the range of factors that influence social interaction. Despite considerable differences among individual chapters, a common theme concerns 
the role of executive function in the child's negotiation of and learning within social interactions.

The focus of Bibok, Carpendale, and Müller's chapter is the dyadic interactions between two-year-olds and their caregivers. Although they concentrate on the nature of parental scaffolding as defined by David Wood and his colleagues, this chapter is an attempt to show that such interactions are far more complex; the effectiveness of parents' attempts to structure the child's cognitive performance is itself in part determined by the child's ability to decipher and contribute to them. Bibok and colleagues take a very close look at the "social structure of scaffolding" to show the complexities of the relationship between social interactions and the child's executive skills, even very early in her or his development.

The focus on scaffolding is broadened even further by Hughes and Ensor, who set out to show that adult-child interactions are only "part of the jigsaw." They point out that the study of social interactions is not incompatible with more biological approaches and even genetic analyses, as long as our interpretation of each is sufficiently flexible. Hughes and Ensor focus on the distinction between the child's direct interactions and the factors that might influence those interactions, notably the family's socioeconomic status and domestic environment. They stress the role of separating executive function from other general cognitive skills such as the child's language level. They show that we need to go beyond the parents' direct scaffolding of their children's skills to understand the contextual influences on them, including the relative "chaos" in the family environment.

Three of the chapters focus exclusively on preschool children. The exception is that of Landry, Smith, and Swank. They use age eight as a pivot around which they consider predictors from the preschool period and sequelae in the children's social functioning in adolescence. The central focus is on developing a measure of social problem solving in eight-yearolds that is ecologically valid and goes beyond reliance on parental report on the social-cognitive skills in middle childhood. They show that social problem solving is predicted by factors in the child's preschool skills and is predictive of their social interactive skills at age 13. Data from Landry et al. clearly show the continuing interplay among social, executive, and general cognitive processes throughout the course of development.

The final data-based chapter extends the focus from social and developmental processes to analyze the role of culture in determining the link between social interactions and executive function. A spate of recent studies has shown that oriental children seem to have highly advanced executive skills, such as working memory (Tardif, So, \& Kaciroti, 2007) and conflict inhibition (Sabbagh, Xu, Carlson, Moses, \& Lee, 2006). In their chapter, Lewis, Koyasu, Oh, Ogawa, Short, and Huang consider this precocious development in terms of two prevailing sets of findings, an apparent pan-cultural link between executive function and social understanding, and associations between family relationships and both these factors. Not only 
is an understanding of cultural processes crucial to our understanding of factors such as a precocious executive functioning, Lewis et al. claim that cross-cultural research can be used to question prevailing Western assumptions about the development of executive skills.

In the final chapter, Stephanie Carlson draws the volume to a close by placing the preceding chapters into a broader theoretical context. She returns to the issue of how we can and should consider the complexity of the term social interaction by examining the trade-off between proximal and distal factors. To do this, Carlson turns, like us, to historical analyses and homes in on the work of George Herbert Mead as a means of understanding the motivational factors underlying self-regulation. The aim of this volume is not to dismiss the explosion of recent work into the neural structure and function of executive processes. Carlson's conclusion is a fitting one for her chapter, this one, and the volume as a whole: a complete grasp of executive function and its development will lie in an approach with multiple levels, from social processes down to the neurophysiological. Such an enterprise will heal some of the rifts that were in evidence 200 years ago when terms such as inhibition and executive control entered into debates about the control of human conduct (Smith, 1992).

\section{References}

Appleton, M., \& Reddy, V. (1996). Teaching three year-olds to pass false belief tests: A conversational approach. Social Development, 5, 275-291.

Ardila, A., Roselli, M., Matute, E., \& Guajardo, S. (2005). The influence of parents' educational level on the development of executive functions. Developmental Neuropsychology, 28, 539-560.

Aron, A. R. (2008). Progress in executive function research: From tasks to functions to regions to networks. Current Directions in Psychological Science, 17, 124-129.

Astington, J. W., \& Baird, J. A. (Eds.). (2005). Why language matters for theory of mind. New York: Oxford University Press.

Baddeley, A. D. (1986). Working memory. Oxford: Oxford University Press.

Baddeley, A. D., \& Hitch, G. J. (1974). Working memory. In G. H. Bower (Ed.), The psychology of learning and motivation, Vol. 8 (pp. 47-89). New York: Academic Press.

Bell, R. Q. (1968). A reinterpretation of the direction of effects in studies of socialization. Psychological Review, 75, 81-95.

Bishop, D.V.M., Aadmodt-Leeper, G., Cresswell, C., McGurk, R., \& Skuse, D. (2001). Individual differences in cognitive planning on the Tower of Hanoi task: Neuropsychological maturity or measurement error? Journal of Child Psychology and Psychiatry, 42, 551-556.

Brace, J. J., Morton, B. J., \& Munakata, Y. (2006). When actions speak louder than words: Improving children's performance on a card-sorting task. Psychological Science, 17, 665-669.

Broadbent, D. E. (1958) Perception and Communication. London: Pergamon.

Bronfenbrenner, U. (1979). The ecology of human development. Cambridge, MA: Harvard University Press.

Bull, R., Espy, K. A., \& Senn, T. E. (2004). A comparison of performance on the Towers of London and Hanoi in young children. Journal of Child Psychology \& Psychiatry, $45,743-754$. 
Carlson, S. M., Davis, A. C., \& Leach, J. G. (2005). Less is more: Executive function and symbolic representation in preschool children. Psychological Science, 16, 609-616.

Duncan, J., Emslie, H., Williams, P., Johnson, R., \& Freer, C. (1996). Intelligence and the frontal lobe: The organisation of goal directed behavior. Cognitive Psychology, 30, 257-303.

Fernyhough, C. (in press). Mediated cognition and social understanding. In B. Sokol, U. Müller, J. I. M. Carpendale, A. Young, \& G. Iarocci (Eds.), Self- and social-regulation: Exploring the relations between social interaction, social cognition, and the development of executive functions. Oxford: Oxford University Press.

Friedman, N. P., et al. (2007). Greater attention problems during childhood predict poorer executive functions in late adolescence. Psychological Science, 18, 893-900.

Friedman, N. P., Miyake, A., Young, S. E., DeFries, J. C., Corley, R. P., \& Hewitt, J. K. (in press). Individual differences in executive functions are almost entirely genetic in origin. Journal of Experimental Psychology: General.

Frye, D., Zelazo, P. D., \& Palfai, T. (1995). Inference and action in early causal reasoning. Cognitive Development, 10, 120-131.

Gerstadt, C. L., Hong, Y. J., \& Diamond, A. (1994). The relationship between cognition and action-performance of children 3 1/2-7 years old on a stroop-like day-night test. Cognition, 53, 129-153.

Hala, S., \& Russell, J. (2001). Executive control within strategic deception: A window on early cognitive development? Journal of Experimental Child Psychology, 80, 112-141.

Hughes, C., \& Russell, J. (1993). Autistic children's difficulty with mental disengagement from an object: Its implications for theories of autism. Developmental Psychology, 29, 498-510.

Huizinga, M., Dolan, C. V., \& van der Molen, M. W. (2006). Age-related change in executive function: Developmental trends and a latent variable analysis. Neuropsychologia, 44, 2017-2036.

Jacques, S., Zelazo, P. D., Kirkham, N. Z., \& Semcesen, T. K. (1999). Rule selection versus rule execution in preschoolers: An error-detection approach. Developmental Psychology, 35, 770-780.

James, William. (1890). Principles of Psychology. New York: Henry Holt.

Karreman, A., van Tuijl, C., van Aken, M.A.G., \& Dekovi, M. (2006). Parenting and selfregulation: A meta-analysis. Infant \& Child Development, 15, 561-579.

Kirkham, N. Z., Cruess, L., \& Diamond, A. (2003). Helping children apply their knowledge to their behavior on a dimension-switching task. Developmental Science, 6, 449-467.

Knight, R. K., \& Stuss, D. T. (Eds.). (2002). Principles of frontal lobe function. Oxford: Oxford University Press.

Kopp, C. (1982). Antecedents of self-regulation: A developmental perspective. Developmental Psychology, 18, 199-214.

Landry, S. H., \& Smith, K. E. (in press). Early social and cognitive precursors and parental support for self-regulation and executive function: Relations from early childhood into adolescence. In B. Sokol, U. Müller, J.I.M. Carpendale, A. Young, \& G. Iarocci (Eds.), Self- and social-regulation: Exploring the relations between social interaction, social cognition, and the development of executive functions. Oxford: Oxford University Press.

Lehto, J. E., Juujarvi, P., Kooistra, L., \& Pulkkinen, L. (2003). Dimensions of executive functioning: Evidence from children. British Journal of Developmental Psychology, $21,59-80$.

Lewis, C., Carpendale, J. I. M., Towse, J., \& Maridaki-Kassotaki, K. (in press). Epistemic flow and the social making of minds. In B. Sokol, U. Müller, J.I.M. Carpendale, A. Young, \& G. Iarocc (Eds.), Self- and social-regulation: Exploring the relations between social interaction, social cognition, and the development of executive functions. Oxford, England: Oxford University Press.

Lewis, C., Solis-Trapala, I., Shimmon, K., \& Diggle, P. (2009). Test order effects in batteries of executive function in preschool children. Manuscript in preparation. 
Luria, A. R. (1961). The role of speech in the regulation of normal and abnormal behavior. Oxford: Pergamon.

Luria, A. R. (1981). Language and cognition. Chichester, England: Wiley.

Mead, G. H. (1910). What objects must psychology presuppose? Journal of Philosophy, Psychology and Scientific Methods, 7, 174-180.

Miller, S. A., Shelton, J., \& Flavell, J. H. (1970). A test of Luria's hypotheses concerning the development of self-regulation. Child Development, 41, 651-665.

Mischel, W., \& Baker, N. (1975) Cognitive transformations of reward objects through instructions. Journal of Personality and Social Psychology, 31, 254-261.

Miyake, A., Friedman, N. P., Emerson, M. J., Witzki, A. H., Howerter, A., \& Wager, T. D. (2000). The unity and diversity of executive functions and their contributions to complex "frontal lobe" tasks: A latent variable analysis. Cognitive Psychology, 41, 49-100.

Moriguchi, Y., Lee, K., \& Itakura, S. (2007). Social transmission of disinhibition in young children. Developmental Science, 10, 481-491.

Munakata, Y., \& Yerys, B. E. (2001). All together now: When dissociations between knowledge and action disappear. Psychological Science, 12, 335-337.

Noble, K. G., McCandliss, B. D., \& Farah, M. J. (2007). Socioeconomic gradients predict individual differences in neurocognitive abilities. Developmental Science, 10, 464-480.

Norman, D. A., \& Shallice, T. (1980). Attention to action: Willed and automatic control of behavior. University of California at San Diego, CHIP Report 99.

Patterson, C. J., \& Mischel, W. (1976). Effects of temptation-inhibiting and task-facilitating plans on self-control. Journal of Personality and Social Psychology, 33, 209-217.

Rabbitt, P. (1997). Introduction: Methodologies and models in the study of executive function. In P. Rabbitt (Ed.), Methodology of frontal and executive function. Hove, England: Psychology Press.

Ritchie, F. K., \& Toner, I. J. (1984). Direct labeling, tester expectancy and delay maintenance behavior in Scottish preschool children. International Journal of Behavioral Development, 7, 333-341.

Rothbart, M., \& Derryberry, D. (1981). Development of individual differences in temperament. In M. Lamb, \& A. Brown (Eds.), Advances in Developmental Psychology, Vol. 1. Hillsdale: NJ: Erlbaum.

Russell, J., Mauthner, N., Sharpe, S., \& Tidswell, T. (1991). The windows task as a measure of strategic deception in preschoolers and autistic subjects. British Journal of Developmental Psychology, 9, 331-349.

Sabbagh, M., Xu, F., Carlson, S. M., Moses, L. J., \& Lee, K. (2006). The development of executive functioning and theory of mind: A comparison of Chinese and U.S. preschoolers. Psychological Science, 17, 74-81.

Shimmon, K. (2005). The development of executive control in young children and its relationship with mental state understanding: A longitudinal study. Ph.D. thesis, Lancaster University, England.

Smith, R. (1992). Inhibition: History and meaning in the sciences of mind and brain. Berkeley and Los Angeles: University of California Press.

Sokol, B. W., \& Müller, U. (Eds.). (2007). The development of self-regulation: Toward the integration of cognition and emotion. (Special Issue.) Cognitive Development, 22, 401-567.

Subbotsky, E. V. (1976). Psychology of partnership relations in preschoolers. Moscow: Moscow University Press (in Russian).

Tardif, T., So, C. W-C., \& Kaciroti, N. (2007). Language and false belief: Evidence for general, not specific effects in Cantonese-speaking preschoolers. Developmental Psychology, 43, 318-340.

Toner, I. J., Moore, L. P., \& Emmons, B. A. (1980). Effect of being labelled on subsequent self-control in children. Child Development, 51, 618-621.

Toner, I. J., \& Smith, R. A., (1977). Age and overt verbalisation in delay-maintenance behavior in children. Journal of Experimental Child Psychology, 24, 123-128. 
Towse, J., Lewis, C., \& Knowles, M. (2007). When knowledge is not enough: The phenomenon of goal neglect in preschool children. Journal of Experimental Child Psychology, 96, 320-332.

Vygotsky, L. S. (1978). Mind in society: The development of higher psychological processes. Cambridge, MA: Harvard University Press.

Zelazo, P. D., \& Jacques, S. (1996). Children's rule use: Representation, reflection and cognitive control. Annals of Child Development, 12, 119-176.

Zelazo, P. D., \& Müller, U. (2002). Executive function in typical and atypical development. In U. Goswami (Ed.), Blackwell handbook of childhood cognitive development (pp. 445-469). Oxford: Blackwell.

Zelazo, P. D., Müller, U., Frye, D., \& Marcovitch, S. (2003). The development of executive function in early childhood. Monographs of the Society for Research in Child Development, 68 (serial no. 274).

CHARLIE LEWIS, professor of family and developmental psychology at Lancaster University, conducts research on the family, especially the role of the father, and young children's understanding of mental states.

JEREMY I. M. CARPENDALE, professor of developmental psychology at Simon Fraser University, conducts research on social cognitive and moral development. 